\title{
WHO's arrived in 2016! An updated weather forecast for integrated brain tumor diagnosis
}

\author{
Arie Perry ${ }^{1}$
}

Published online: 13 June 2016

(C) The Japan Society of Brain Tumor Pathology 2016

After much anticipation, the updated 2016 World Health Organization (WHO) brain tumor classification blue book has finally arrived [6, 8]. For the first time in the CNS series, a number of common entities are no longer defined by morphology alone, but also by signature molecular alterations, i.e., an 'integrated diagnosis'. The basic concepts for this new approach were initially derived from the 'WHO's Next?' consensus meeting in Haarlem, The Netherlands, 2 years earlier [7], followed by a more official WHO meeting in June of 2015, wherein international experts met to debate and resolve remaining controversies. Given the dramatic shift in clinical practice that was likely to come from such integrated diagnoses, I wrote an editorial in early 2014 entitled 'A blustery wind of change', highlighting a few of the upcoming challenges to be discussed by the Haarlem group in balancing clinical desires with the needs of routine daily practice, incorporating molecular definitions in a practical fashion, and adjusting for highly variable resources available across the globe [10]. Ending the editorial with 'stay tuned for future weather forecasts on this changing wind', it seems appropriate now to provide a bit of feedback.

The main impetus for the 2016 changes in practice arose from the recognition that within a single WHO 2007 entity, such as glioblastoma or medulloblastoma, multiple biologically distinct molecular subtypes exist, often with their own unique prognostic and therapeutic implications $[12,16]$. Furthermore, some morphology-based criteria were too vague for clinical practice, yielding tremendous interobserver variability and poor diagnostic

Arie Perry

Arie.Perry@ucsf.edu

1 San Francisco, USA reproducibility, even amongst expert consultants, the most egregious example being that of oligoastrocytoma [11]. Given the molecular advances in the last decade, it is, perhaps, not surprising that the greatest WHO modifications involved the diffuse gliomas and embryonal neoplasms. Since a comprehensive overview of all new entities, variants, and patterns is beyond the scope of this editorial, the reader is instead referred to a recent review for further details [8]. Nonetheless, a few highlights and their impact on clinical practice are considered below.

For the adult gliomas, the most critical initial stratifier is now the presence or absence of IDH1 or IDH2 mutations, with IDH-mutant gliomas further classified as oligodendroglioma in the presence of $1 \mathrm{p} / 19 \mathrm{q}$ codeletion or astrocytoma in its absence (the loss of ATRX expression also representing a useful surrogate marker; see below). With these definitions, the diagnosis of 'oligoastrocytoma', along with the grade III 'anaplastic oligoastrocytoma', and the grade IV counterpart, 'glioblastoma with an oligodendroglial component', become all but extinct, since nearly all will fall into one of the pure categories upon molecular characterization. In contrast, grading continues to be based on classic histologic criteria, although early data suggest that these may be inadequate for the IDH-mutant tumors, as no survival time differences were recently found between corresponding WHO grade II and III examples [9]. Nevertheless, grade II and III astrocytoma patients do considerably better than those with IDH-mutant glioblastomas, suggesting that grade still plays some role [2], perhaps, with the criteria for anaplasia needing to be reconsidered. In contrast, the adult IDH-wildtype counterparts often behave like glioblastoma [4], even when appearing lower grade histologically, with many cases presumed to represent early or under-sampled IDH-wildtype glioblastoma, especially if appearing 
anaplastic on histology, the patient is elderly, and/or there is a rim-enhancement pattern on MR imaging. However, one must be careful not to extrapolate this concept too far in the cases resembling a WHO II diffuse glioma, particularly in younger patients, as one should also exclude potentially favorable IDH-wildtype entities, such as ganglioglioma, pilocytic astrocytoma, pleomorphic xanthoastrocytoma, pediatric-type low-grade gliomas, etc. Furthermore, another IDH-wildtype consideration designated 'diffuse midline glioma, H3 K27M-mutant' was added to reflect a morphologically diverse, but molecularly distinct category of aggressive midline glioma (mostly thalamic, brainstem, and spinal), encountered mostly in children and young adults [14].

For embryonal neoplasms, the main changes included the addition of molecularly defined medulloblastomas, a new entity designated embryonal tumor with multilayered rosettes (ETMR), and the elimination of 'primitive neuroectodermal tumor' or PNET from the official lexicon, the term instead being reserved for the peripheral PNET/Ewing sarcoma subtype that may, nonetheless, present within the CNS as a dural or paraspinal mass on occasion. The latter also reflects the appreciation that most cases previously diagnosed as 'CNS PNET' can now be reclassified as other entities, such as glioblastoma/high-grade astrocytoma, anaplastic ependymoma, choroid plexus carcinoma, and more specific integrated embryonal tumor diagnoses, including ETMR, C19MC-altered (most often a chromosome 19 microRNA cluster amplification), and atypical teratoid/rhabdoid tumor, with inactivation of $S M A R C B 1$ or SMARCA4 genes (or loss of INI1 or BRG1 expression) [15]. For those that cannot be further classified, the term 'CNS embryonal tumor, NOS' was created, with the expectation that this wastebasket diagnosis would shrink over time, as more specific entities continue to be carved out. For medulloblastoma, morphologic variants were retained, as it is recognized that some have independent prognostic value, but molecular categories were added, with the recommendation that integrated diagnoses include both. Molecular variants now include WNT-activated; SHH-activated and TP53-wildtype; SHH-activated and TP53-mutant; and non-WNT/non-SHH, with the subdivision of the SHH-activated variant reflecting the recognition that those with TP53 mutation and/or strong widespread p53 positivity have a particularly dismal prognosis $[3,12,18]$. In addition, these tumors differ from their TP53-wildtype counterparts by presenting mostly between the ages of 3 and 17 years, often showing anaplastic features, being resistant to current therapies (including SMO inhibitors), and commonly arising in patients with germline TP53 mutations (i.e., Li-Fraumeni syndrome), thus necessitating both genetic counseling for the family and novel patient management strategies [5, 12]. The less specific
non-WNT/non-SHH category is, unfortunately, the largest, but reflects the technical difficulties in reliably distinguishing molecular groups 3 and 4; nevertheless, those with genomic or epigenomic techniques capable of making this distinction can opt to utilize these designations instead.

It should be noted that for the many entities for which we have insufficient understanding or pathognomonic molecular alterations, the diagnosis remains based on the traditional histopathology alone. For the integrated diagnoses though, having now practiced these WHO 2016 guidelines myself, corresponded with many colleagues adjusting their practice, and given a number of international updates, my main feedback has been that both pathologists and neuro-oncologists are pleased by the increased objectivity and diagnostic reproducibility afforded by the 2016 WHO scheme. As with anything new, however, there is also some associated anxiety and the sense by a few that the WHO has either gone too far or hasn't gone far enough. In their challenge to reach the right balance between the 'haves' and 'have-nots', the WHO strove to create a system that was flexible enough to simultaneously not hold back those with abundant resources, while not excluding those with little to no molecular access. Naturally, the latter is more challenging to achieve than the former, since this classification scheme puts no restrictions on anyone wishing to go beyond the recommended guidelines if they so desire. In contrast, if a pathologist has access to nothing more than routine $\mathrm{H} \& \mathrm{E}$ sections, then there are, indeed, integrated diagnoses that he or she cannot render. This issue was resolved in the WHO 2016 by providing 'not otherwise specified' (NOS) diagnostic options, for which the criteria have changed little from the 2007 rendition. In other words, if IDH and $1 \mathrm{p} / 19 \mathrm{q}$ status cannot be assessed, then one may still render diagnoses, such as 'diffuse astrocytoma, NOS', 'oligodendroglioma, NOS', 'oligoastrocytoma, NOS', 'glioblastoma, NOS', etc. based purely on histopathology. Nonetheless, it is likely that oncologists will become decreasingly satisfied with such descriptive diagnoses if they know that a nearby pathology practice is capable of providing more accurate interpretations. If at all possible then, it is incumbent on current pathology practices to upgrade their testing menus as needed or forward their cases to centers with appropriate resources. With this in mind, I'm often asked how such an approach can be rendered in a general pathology lab with limited funds.

A recently published survey of 314 hospitals/medical centers from 48 countries revealed that, in fact, $79 \%$ currently utilize the WHO scheme for classifying their brain tumors with $75 \%$ having access to at least some molecular testing, including $1 \mathrm{p} / 19 \mathrm{q}$ testing (72 \%), MGMT promoter methylation analysis (53\%), BRAF sequencing $(50 \%)$, and IDH1 mutation assessment (47\%) [1]. Given 
that many (but not all) of the signature molecular alterations can now also be detected by surrogate immunostains and that nearly all pathology labs around the world utilize immunohistochemistry (IHC), one can further augment these figures. For instance, like most centers, we have now developed practical diagnostic algorithms at UCSF, with IHC often being applied initially. For instance, we first screen all diffuse gliomas with an IDH1 R132H immunostain, as this can detect nearly $90 \%$ of all IDH mutations [13]. Given the additional high frequency of ATRX loss in IDH-mutant astrocytomas, this immunostain further aids in our exclusion of oligodendrogliomas. As such, we do not perform anything beyond IHC for our IDH-mutant astrocytomas showing ATRX loss (WHO grades II-IV). Instead, we save $1 \mathrm{p} / 19 \mathrm{q}$ testing for IDH1 $\mathrm{R} 132 \mathrm{H}$ positive gliomas that have retained ATRX expression and/or show some oligodendroglial features on routine morphology. Similarly, IDH1 and IDH2 sequencing is reserved as a second step in the algorithm for all IDH1 R132H immunonegative diffuse gliomas in younger patients (e.g., <55 years of age), those with a long clinical history or prior lower grade precursor glioma, and IDH1 R132H immunonegative gliomas with ATRX loss from patients of any age. We also add an H3 K27M mutant protein immunostain for all diffuse gliomas involving midline structures. For medulloblastoma subtyping, a number of surrogate immunostains are commercially available for the WNT-activated (e.g., nuclear beta catenin) and SHH-activated (e.g., GAB1) variants, along with p53 IHC being useful to distinguish the TP53-mutant from wildtype subsets; nevertheless, this initial panel is typically supplemented with FISH or other molecular studies to detect monosomy 6, i17q, MYC amplification, and $M Y C N$ amplification, among others. As with molecular pathology, in general, the range of IHC surrogates continues to expand and will no doubt, continue to evolve rapidly [17]. Similarly, the WHO 2016 scheme represents an important first step in the integrated diagnosis approach and will surely continue to advance in future iterations.

In summary, I feel that the blustery wind has passed, our house has a stronger foundation than ever, and there is some beautiful, sunny weather in our forecast.

\section{References}

1. Andreiuolo F, Mazeraud A, Chretien F, Pietsch T (2016) A global view on the availability of Methods and information in the neuropathological diagnostics of CNS tumors: Results of an International Survey Among Neuropathological Units. Brain Pathol. doi:10.1111/bpa.12383

2. Eckel-Passow JE, Lachance DH, Molinaro AM, Walsh KM, Decker PA, Sicotte H, Pekmezci M, Rice T, Kosel ML, Smirnov IV, Sarkar G, Caron AA, Kollmeyer TM, Praska CE, Chada AR,
Halder C, Hansen HM, McCoy LS, Bracci PM, Marshall R, Zheng S, Reis GF, Pico AR, O'Neill BP, Buckner JC, Giannini C, Huse JT, Perry A, Tihan T, Berger MS, Chang SM, Prados MD, Wiemels J, Wiencke JK, Wrensch MR, Jenkins RB (2015) Glioma Groups Based on $1 \mathrm{p} / 19 \mathrm{q}$, IDH, and TERT Promoter Mutations in Tumors. New Engl J Med 372:2499-2508. doi:10. 1056/NEJMoa1407279

3. Gessi M, von Bueren AO, Rutkowski S, Pietsch T (2012) p53 expression predicts dismal outcome for medulloblastoma patients with metastatic disease. J Neurooncol 106:135-141. doi:10.1007/ s11060-011-0648-8

4. Hartmann C, Hentschel B, Wick W, Capper D, Felsberg J, Simon M, Westphal M, Schackert G, Meyermann R, Pietsch T, Reifenberger G, Weller M, Loeffler M, von Deimling A (2010) Patients with IDH1 wild type anaplastic astrocytomas exhibit worse prognosis than IDH1-mutated glioblastomas, and IDH1 mutation status accounts for the unfavorable prognostic effect of higher age: implications for classification of gliomas. Acta Neuropathol 120:707-718. doi:10.1007/s00401-010-0781-z

5. Kool M, Jones DT, Jager N, Northcott PA, Pugh TJ, Hovestadt V, Piro RM, Esparza LA, Markant SL, Remke M, Milde T, Bourdeaut F, Ryzhova M, Sturm D, Pfaff E, Stark S, Hutter S, SekerCin H, Johann P, Bender S, Schmidt C, Rausch T, Shih D, Reimand J, Sieber L, Wittmann A, Linke L, Witt H, Weber UD, Zapatka M, Konig R, Beroukhim R, Bergthold G, van Sluis P, Volckmann R, Koster J, Versteeg R, Schmidt S, Wolf S, Lawerenz C, Bartholomae CC, von Kalle C, Unterberg A, HeroldMende C, Hofer S, Kulozik AE, von Deimling A, Scheurlen W, Felsberg J, Reifenberger G, Hasselblatt M, Crawford JR, Grant GA, Jabado N, Perry A, Cowdrey C, Croul S, Zadeh G, Korbel JO, Doz F, Delattre O, Bader GD, McCabe MG, Collins VP, Kieran MW, Cho YJ, Pomeroy SL, Witt O, Brors B, Taylor MD, Schuller U, Korshunov A, Eils R, Wechsler-Reya RJ, Lichter P, Pfister SM (2014) Genome sequencing of SHH medulloblastoma predicts genotype-related response to smoothened inhibition. Cancer Cell 25:393-405. doi:10.1016/j.ccr.2014.02.004

6. Louis DN, Ohgaki H, Wiestler OD, Cavenee WK, Ellison DW, Figarella-Branger D, Perry A, Reifenberger G, von Deimling A (2016) WHO classification of tumours of the central nervous system (Revised, 4th edn. IARC, Lyon

7. Louis DN, Perry A, Burger P, Ellison DW, Reifenberger G, von Deimling A, Aldape K, Brat D, Collins VP, Eberhart C, FigarellaBranger D, Fuller GN, Giangaspero F, Giannini C, Hawkins C, Kleihues P, Korshunov A, Kros JM, Beatriz Lopes M, Ng HK, Ohgaki H, Paulus W, Pietsch T, Rosenblum M, Rushing E, Soylemezoglu F, Wiestler O, Wesseling P (2014) International society of neuropathology-haarlem consensus guidelines for nervous system tumor classification and grading. Brain Pathol 24:429-435. doi:10.1111/bpa.12171

8. Louis DN, Perry A, Reifenberger G, von Deimling A, FigarellaBranger D, Cavenee WK, Ohgaki H, Wiestler OD, Kleihues P, Ellison DW (2016) The 2016 World Health Organization classification of tumors of the central nervous system: a summary. Acta Neuropathol 131:803-820. doi:10.1007/s00401-016-1545-1

9. Olar A, Wani KM, Alfaro-Munoz KD, Heathcock LE, van Thuijl HF, Gilbert MR, Armstrong TS, Sulman EP, Cahill DP, VeraBolanos E, Yuan Y, Reijneveld JC, Ylstra B, Wesseling P, Aldape KD (2015) IDH mutation status and role of WHO grade and mitotic index in overall survival in grade II-III diffuse gliomas. Acta Neuropathol 129:585-596. doi:10.1007/s00401-0151398-Z

10. Perry A (2014) A blustery wind of change. Brain Pathol 24:i-ii. doi:10.1111/bpa.12143

11. Perry A, Wesseling $P$ (2016) Histologic classification of gliomas. Handbook Clin Neurol 134:71-95. doi:10.1016/B978-0-12802997-8.00005-0 
12. Ramaswamy V, Remke M, Bouffet E, Bailey S, Clifford SC, Doz F, Kool M, Dufour C, Vassal G, Milde T, Witt O, von Hoff K, Pietsch T, Northcott PA, Gajjar A, Robinson GW, Padovani L, Andre N, Massimino M, Pizer B, Packer R, Rutkowski S, Pfister SM, Taylor MD, Pomeroy SL (2016) Risk stratification of childhood medulloblastoma in the molecular era: the current consensus. Acta Neuropathol 131:821-831. doi:10.1007/s00401016-1569-6

13. Reuss DE, Sahm F, Schrimpf D, Wiestler B, Capper D, Koelsche C, Schweizer L, Korshunov A, Jones DT, Hovestadt V, Mittelbronn M, Schittenhelm J, Herold-Mende C, Unterberg A, Platten M, Weller M, Wick W, Pfister SM, von Deimling A (2015) ATRX and IDH1-R132H immunohistochemistry with subsequent copy number analysis and IDH sequencing as a basis for an "integrated" diagnostic approach for adult astrocytoma, oligodendroglioma and glioblastoma. Acta Neuropathol 129:133-146. doi:10.1007/s00401-014-1370-3

14. Solomon DA, Wood MD, Tihan T, Bollen AW, Gupta N, Phillips JJ, Perry A (2015) Diffuse midline gliomas with histone H3K27M mutation: a series of 47 cases assessing the spectrum of morphologic variation and associated genetic alterations. Brain Pathol. doi:10.1111/bpa.12336

15. Sturm D, Orr BA, Toprak UH, Hovestadt V, Jones DT, Capper D, Sill M, Buchhalter I, Northcott PA, Leis I, Ryzhova M, Koelsche C, Pfaff E, Allen SJ, Balasubramanian G, Worst BC, Pajtler KW, Brabetz S, Johann PD, Sahm F, Reimand J, Mackay A, Carvalho DM, Remke M, Phillips JJ, Perry A, Cowdrey C, Drissi R, Fouladi M, Giangaspero F, Lastowska M, Grajkowska W, Scheurlen W, Pietsch T, Hagel C, Gojo J, Lotsch D, Berger W, Slavc I, Haberler C, Jouvet A, Holm S, Hofer S, Prinz M, Keohane C, Fried I, Mawrin C, Scheie D, Mobley BC, Schniederjan MJ, Santi M, Buccoliero AM, Dahiya S, Kramm CM, von Bueren AO, von Hoff K, Rutkowski S, Herold-Mende C, Fruhwald MC, Milde T, Hasselblatt M, Wesseling P, Rossler J, Schuller U, Ebinger M, Schittenhelm J, Frank S, Grobholz R, Vajtai I, Hans V, Schneppenheim R, Zitterbart K, Collins VP, Aronica E, Varlet P, Puget S, Dufour C, Grill J, Figarella-Branger D, Wolter M, Schuhmann MU, Shalaby T, Grotzer M, van Meter T, Monoranu CM, Felsberg J, Reifenberger G, Snuderl M, Forrester LA, Koster J, Versteeg R, Volckmann R, van Sluis P, Wolf S, Mikkelsen T, Gajjar A, Aldape K, Moore AS, Taylor MD, Jones C, Jabado N, Karajannis MA, Eils R, Schlesner M, Lichter P, von Deimling A,
Pfister SM, Ellison DW, Korshunov A, Kool M (2016) New brain tumor entities emerge from molecular classification of CNSPNETs. Cell 164:1060-1072. doi:10.1016/j.cell.2016.01.015

16. Sturm D, Witt H, Hovestadt V, Khuong-Quang DA, Jones DT, Konermann C, Pfaff E, Tonjes M, Sill M, Bender S, Kool M, Zapatka M, Becker N, Zucknick M, Hielscher T, Liu XY, Fontebasso AM, Ryzhova M, Albrecht S, Jacob K, Wolter M, Ebinger M, Schuhmann MU, van Meter T, Fruhwald MC, Hauch H, Pekrun A, Radlwimmer B, Niehues T, von Komorowski G, Durken M, Kulozik AE, Madden J, Donson A, Foreman NK, Drissi R, Fouladi M, Scheurlen W, von Deimling A, Monoranu C, Roggendorf W, Herold-Mende C, Unterberg A, Kramm CM, Felsberg J, Hartmann C, Wiestler B, Wick W, Milde T, Witt O, Lindroth AM, Schwartzentruber J, Faury D, Fleming A, Zakrzewska M, Liberski PP, Zakrzewski K, Hauser P, Garami M, Klekner A, Bognar L, Morrissy S, Cavalli F, Taylor MD, van Sluis P, Koster J, Versteeg R, Volckmann R, Mikkelsen T, Aldape K, Reifenberger G, Collins VP, Majewski J, Korshunov A, Lichter P, Plass C, Jabado N, Pfister SM (2012) Hotspot Mutations in H3F3A and IDH1 Define Distinct Epigenetic and Biological Subgroups of Glioblastoma. Cancer Cell 22:425-437. doi:10.1016/j.ccr.2012.08.024

17. Tanboon J, Williams EA, Louis DN (2015) The diagnostic use of immunohistochemical surrogates for signature molecular genetic alterations in gliomas. J Neuropathol Exp Neurol. doi:10.1093/ jnen/nlv009

18. Zhukova N, Ramaswamy V, Remke M, Pfaff E, Shih DJ, Martin DC, Castelo-Branco P, Baskin B, Ray PN, Bouffet E, von Bueren AO, Jones DT, Northcott PA, Kool M, Sturm D, Pugh TJ, Pomeroy SL, Cho YJ, Pietsch T, Gessi M, Rutkowski S, Bognar L, Klekner A, Cho BK, Kim SK, Wang KC, Eberhart CG, FevreMontange M, Fouladi M, French PJ, Kros M, Grajkowska WA, Gupta N, Weiss WA, Hauser P, Jabado N, Jouvet A, Jung S, Kumabe T, Lach B, Leonard JR, Rubin JB, Liau LM, Massimi L, Pollack IF, Shin Ra Y, Van Meir EG, Zitterbart K, Schuller U, Hill RM, Lindsey JC, Schwalbe EC, Bailey S, Ellison DW, Hawkins C, Malkin D, Clifford SC, Korshunov A, Pfister S, Taylor MD, Tabori U (2013) Subgroup-specific prognostic implications of TP53 mutation in medulloblastoma. J Clin Oncol Off J Am Soc Clin Oncol 31:2927-2935. doi:10.1200/JCO.2012. 48.5052 